\title{
Ressignificação da existência e do cotidiano de pessoas que vivem com HIV
}

\author{
Re-signification of the existence and daily life of people living with HIV \\ Resignificación de la existencia y del cotidiano de personas que viven con VIH \\ Marcia Pereira Gomes ${ }^{*}$, Fabiana Barbosa Assumpção de Souza², Antônio Marcos Tosoli Gomes ${ }^{3}$, \\ Girlene Alves da Silva ${ }^{4}$, Diogo Jacintho Barbosa ${ }^{5}$, André Luis Brugger e Silva ${ }^{6}$
}

Como citar esse artigo. Gomes, MP; de Souza, FBA; Gomes, AMT; da SIlva, GA; Barbosa, DJ; e Silva, ALB; Barbosa, DJ; e Silva, ALB. Ressignificação da existência e do cotidiano de pessoas que vivem com HIV . Revista PróUniverSUS. 2019 Jan./Jun.; 10 (1): 0206

\begin{abstract}
Resumo
Estudo descritivo, qualitativo, parte de um estudo que analisou as condições de vida pessoas vivendo com HIV (PVHIV) e suas implicações para a qualidade de vida. Objetivo descrever e analisar como os sujeitos ressignificam o cotidiano buscando a continuidade e normalidade da vida . Foram 19 entrevistas, com pessoas vivendo com HIV maiores de 18 anos até 70 anos em uso de terapia antirretroviral, e matriculados em um ambulatório de imunologia de um Hospital Universitário. Da análise, emergiram cinco categorias dividas em dois eixos. Neste estudo foi trabalhado o eixo que traduziu a vida e sua continuidade no contexto de enfrentamento do HIV, abordando a normalidade e a busca pela adaptação a soropositividade. Conclui-se que os sujeitos ressignificam a vivência do cotidiano amparados no trabalho na rede social de apoio e em elementos que expressam religiosidade/ espiritualidade e se adaptam a condição de soropositividade.
\end{abstract}

Palavras-chave: Espiritualidade, HIV/aids, PVHIV, Religiosidade.

\begin{abstract}
Descriptive and qualitative study, that analyzed the living conditions of people living with HIV (PLHIV) and its implications for quality of life. The objective was to describe and analyze how subjects re-signify everyday life seeking the continuity and normality of life. There were 19 interviews with people living with HIV over 18 years of age up to 70 years of antiretroviral therapy and enrolled in an immunology outpatient clinic of a University Hospital. The results showed five categories divided into two axes. In this study the axis that translated life and its continuity in the context of HIV coping was addressed, addressing the normality and the search for adaptation to seropositivity. It is concluded that the subjects re-signify the daily life based on work in the social support network and in elements that express religiosity / spirituality and adapt to the condition of seropositivity.
\end{abstract}

Keywords: Spirituality, HIV / AIDS, PVHIV, Religiosity.

\section{Resumen}

Estudio descriptivo y cualitativo, que analizó las condiciones de vida de las personas que viven con VIH (PVVIH) y sus implicaciones para la calidad de vida. El objetivo era describir y analizar cómo los sujetos re-significan la vida cotidiana buscando la continuidad y la normalidad de la vida. Hubo 19 entrevistas con personas con VIH mayores de 18 años y hasta 70 años de terapia antirretroviral y se inscribieron en una clínica ambulatoria de inmunología de un hospital universitario. Los resultados mostraron cinco categorías divididas en dos ejes. En este estudio se abordó el eje que traducía la vida y su continuidad en el contexto de la cofia del VIH, abordando la normalidad y la búsqueda de la adaptación a la seropositividad. Se concluye que los sujetos vuelven a significar la vida diaria basada en el trabajo en la red de apoyo social y en elementos que expresan la religiosidad / espiritualidad y se adaptan a la condición de seropositividad.

Palabras clave: Cultura de la organización; Calidad de la asistencia; Seguridad del paciente; Enfermería.

Afiliação dos autores: 1. Enfermeira. Mestre em Enfermagem pela UNIRIO. RJ, Brasil.

2. Enfermeira. Pós-Doutora em Enfermagem. Professora da EEAP/UNIRIO. RJ, Brasil.

3. Enfermeiro. Doutor em Enfermagem. Professor e Coordenador Adjunto do Programa de Pós-Graduação em Enfermagem da UERJ. RJ, Brasil.

4. Enfermeira. Doutora em Enfermagem. Professora Associada da faculdade de enfermagem da UFJF, MG, Brasil.

5. Enfermeiro. Doutorando em Enfermagem da UERJ RJ, Brasil.

6. Enfermeiro. Mestre em Enfermagem pela UNIRIO. RJ, Brasil

* Email de correspondencia: Espiritualidad, VIH /sida, Religiosidad 


\section{Introdução}

A descoberta da síndrome da imunodeficiência humana (aids) e seu agente etiológico, o HIV foi um evento marcante e revolucionário na saúde mundial em meados dos anos 80 . Atualmente cerca de 36,9 milhoes de pessoas vivem com HIV no mundo ${ }^{1}$ e cada vez menos pessoas adoecem e desenvolvem aids, muito em parte pelo advento dos antirretrovirais, pelas novas tecnologias de prevenção e pela recomendação do Ministério da Saúde (MS) que desde 2013, oferece o tratamento para todas as pessoas diagnosticadas com $\mathrm{HIV}^{2}$. A imagem da morte foi sendo substituída pela expectativa de vida, ressignificando o conceito da doença, que entrou em um processo de cronificação ${ }^{3}$.

O presente artigo é parte de um estudo que analisou as condições de vida pessoas vivendo com HIV (PVHIV) e suas implicações para a qualidade de vida. Como objeto deste trabalho está a ressignificação da vivência do cotidiano ancorados na esperança trazida pela medicação, trabalho e religiosidade. Objetiva-se descrever e analisar como os sujeitos ressignificam o cotidiano buscando a normalidade da vida através da medicação, do trabalho e religiosidade se adaptando a condição de soropositividade.

\section{Metodologia}

Estudo qualitativo descritivo, onde os participantes foram pessoas vivendo com HIV/Aids (PVHA) maiores de 18 anos até 70 anos em uso de terapia antirretroviral, matriculados no ambulatório de imunologia de um Hospital Universitário no município do Rio de janeiro. A coleta de dados aconteceu no período de julho a setembro de 2015 , e se deu por meio de entrevistas semiestruturadas, na primeira parte do instrumento constavam dados para caracterização do perfil dos participantes e na segunda parte questões que buscavam atingir os objetivos do estudo. Atendeu a resolução do Conselho Nacional de Saúde (CNS) 466/2012, aprovada no CEP da instituição (CAAE: 45955315.0.0000.5285). Os dados quantitativos foram tabulados no programa Microsoft Excel ${ }^{\circledR}$ versão 2010, e os dados qualitativos organizados no software Interface de R pour les Analyses Multidimensionnelles de Textes et de Questionnaires (Iramuteq) Alpha 7.2, sendo este uma ferramenta da tecnologia da informação. $\mathrm{O}$ tratamento estatístico de dados provenientes de fontes como a entrevista, efetuado com o auxílio de softwares, tem se mostrado cada vez mais frequente e válido para análises de corpus volumoso ${ }^{4}$. Este auxilia na realização da análise lexical, que consiste num tipo específico de análise de dados, que trata especificamente da análise de material verbal transcrito. É parte da análise de conteúdo, sendo relevante aos estudos sobre pensamentos, crenças e opiniões em relação a determinado fenômeno produzido ${ }^{5}$. Dentre as diversas análises realizadas pelo software, a Classificação Hierárquica Descendente (CHD) será utilizada neste trabalho, esta se caracteriza por organizar os dados em um dendograma de classes , ilustrando a relação entre elas, e executa cálculos (teste de qui-quadrado) e fornece resultados que nos permitem a descrição de cada uma das classes por palavras estatisticamente significativas, ligadas a estas. Fornece também os segmentos de texto (ST) mais característicos de cada classe, permitindo sua contextualização ${ }^{4,5}$.

\section{Resultados e discussão}

Os resultados descritos foram obtidos a partir da análise lexical pelo software Iramuteq das respostas à questão 2.12 "Fale de algo mais que assim desejar" do roteiro de entrevista. Foram identificadas na análise 19 linhas estreladas (ou com asteriscos), determinando o número de unidades de contexto inicial (UCI), que correspondem ao número de entrevistas analisadas. A análise encontrou 43 segmentos de texto e os classificou e analisou na Classificação Hierárquica Descendente (CHD). Esta dividiu o corpus em seis classes e o subdividiu em três momentos.

A abordagem se dará no subeixo 2.1 derivado do eixo 2 congregando as classes 5 "A busca da normalidade da vida: medicação, esperança, religiosidade e trabalho" e a classe 1 "A continuidade da vida e sua adaptação à condição de soropositividade: a ressignificação da existência e do cotidiano".

A classe 5 representou $13,9 \%$ do material analisado com 6 ST mais característicos e se destacaram as palavras normal $\left(\mathrm{x}^{2}=27,2\right)$ vida $\left(\mathrm{x}^{2}=11,77\right)$ Deus $\left(\mathrm{x}^{2}\right.$ $=4,77)$ e melhor $\left(x^{2}=3,2\right)$. A palavra normal fortemente associada à classe seguida da palavra vida, revela uma vida que deve continuar seguindo sua normalidade mesmo após o diagnóstico do HIV enquanto que as palavras Deus e melhor revelam elementos religiosos que podem contribuir e fortalecer essa normalidade do cotidiano proporcionando um remodelamento numa construção melhor da vida . Manter-se vivo em potencialidade, querendo viver a vida como ela é, repleta de sentidos e significados faz com PVHIV percebam que embora algumas mudanças ocorram no dia-a-dia, suas condições de vida são boa ou ótima refletindo positivamente na qualidade de vida Isso ai é do decorrer do dia, do ano, alguns medicamentos só, mas viver a vida vai viver normal (*suj_29). Inúmeros são os desafios após o diagnóstico como o medo, o estigma, o preconceito, as mudanças no corpo, na vida diária, a necessidade de adesão a uma terapia medicamentosa entre outros. As mudanças vão sendo percebidas à medida que se vai convivendo com a nova condição, 


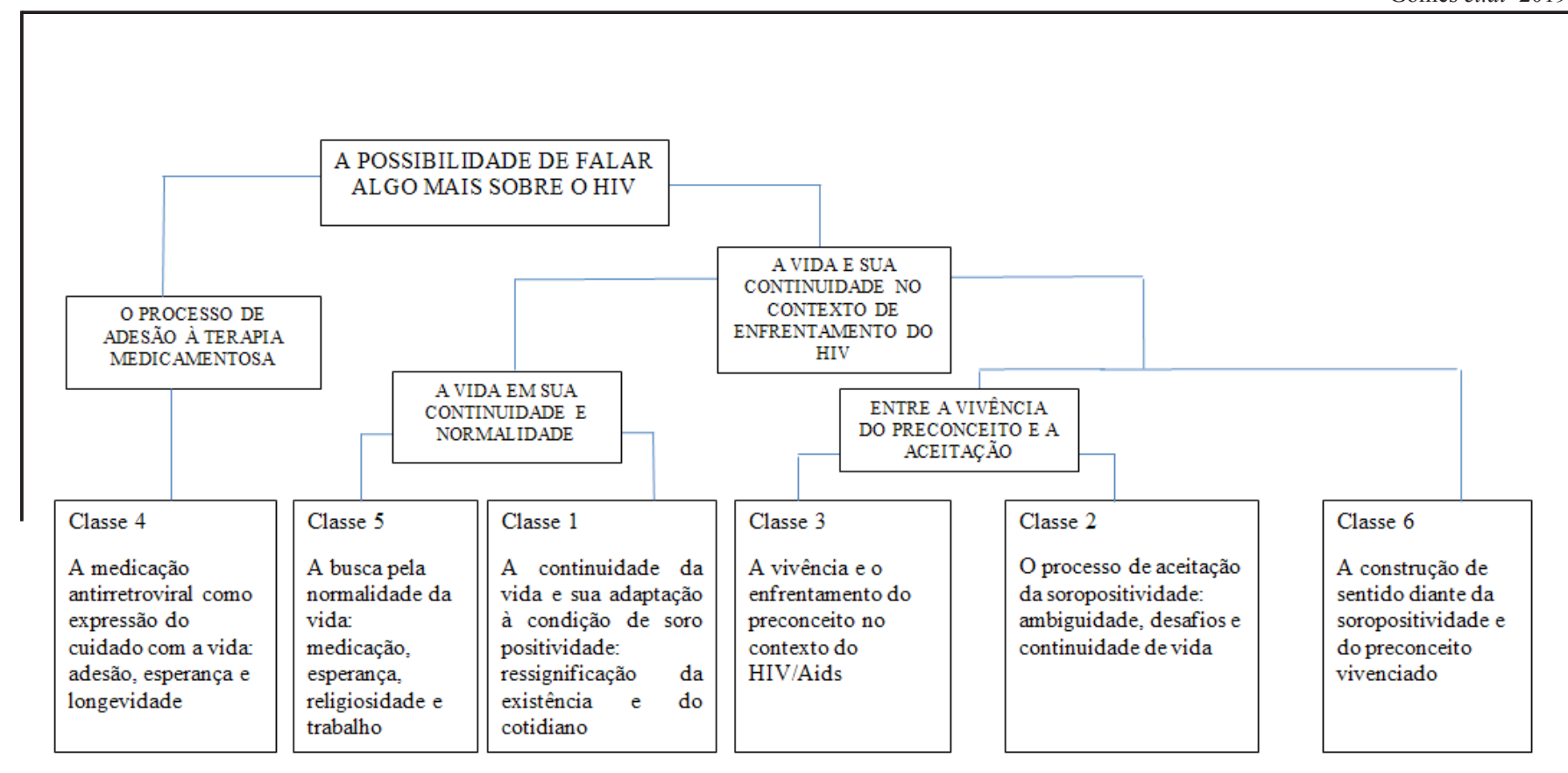

Figura 1

Fonte: A autora (2017) adaptado de Iramuteq (2017).

mas há um reforço que a vida vai continuar sendo vivida de maneira normal, Vida normal. (*suj_20). Quando as mudanças trazidas pelo HIV se tornam conscientes, a adesão ao tratamento pode ser favorecida aumentando a sobrevida, a expectativa de vida e também a motivação, pois além de conviver com uma síndrome que pode trazer limitações, a PVHIV ainda enfrenta uma patologia estigmatizante ${ }^{6,7}$ e reconhecer a importância da vida, faz com que os desafios possam ser perpassados e que se reúna força necessária para realizar o tratamento. O desejo de viver é tão grande que contribui para a superação das barreiras ${ }^{8}$. A condição atual da soropositividade para o HIV como condição crônica de saúde, faz com que comumente esta seja comparada a doenças como câncer ou diabetes, que precisam de tratamento e acompanhamento. A comparação entre aids e outras doenças crônicas é uma tentativa de normalização da mesma ${ }^{3}$.

$\mathrm{Na}$ busca de dar continuidade a normalidade da vida, o trabalho se destaca como fator positivo para o enfrentamento dos desafios trazidos pela soropositividade Mas assim, tem que viver normal, ter a vida normal, trabalhar normal, nessa parte eu faço tudo como antes, principalmente trabalhar, porque trabalhar é o melhor remédio, depressão para mim é para quem não tem o que fazer. (*suj_24) o trabalho é relatado com sentido de utilidade e pertencimento mantendo o sujeito em numa rotina diária e sendo fator de fortalecimento para não experenciar a depressão por exemplo. Indivíduos empregados apresentam melhor qualidade de vida, o emprego proporciona benefícios financeiros sendo uma fonte de apoio social, emocional e de identidade ${ }^{9,10}$.

Além do trabalho, da família e dos amigos um outro ponto de ancoragem e fortalecimento do sentido da vida são aspectos ligados a espiritualidade $\mathrm{e}$ religiosidade, Para que ele confiasse e entregasse nas mãos de Deus, porque Deus tem o melhor para as nossas vidas. (*suj_53) Após o diagnóstico, muitas pessoas procuraram o apoio espiritual e/ou religioso o que gera em si um grande sentimento de esperança e força para o enfrentamento da doença com sentimento de conforto e perseverança ${ }^{3}$. A fé é reconhecida como fonte que alimenta o seguimento da vida. Primeiramente se agarre em Deus, depois confia nas pessoas que Deus colocou na vida pra te ajudar, sejam os médicos, os enfermeiros, os dentistas. (*suj_18). Dentre os profissionais de saúde é o enfermeiro quem muitas das vezes tem um convívio mais longo e próximo do paciente facilitando o estabelecimento de vínculo e se tornando um importante aliado, uma vez que esta pode ser uma fase em que o corpo fisico e também o psicológico podem estar abalados, e o acolhimento estimula principalmente a esperança oferecendo suporte emocional ampliando assim o desejo de viver ${ }^{3,6,7}$. Seguir a vida dentro de uma normalidade é para PVHIV, uma forma de inclusão na sociedade, ser portador de HIV não a torna uma pessoa diferente, ela tem uma doença crônica que exige tratamento, acompanhamento e adequação de alguns hábitos de vida.

A classe 1 se expressou em 13,9\% do material analisado com 6 ST mais caracteristicos e como palavras em destaque trouxe viver $(\mathrm{x} 2=16,41)$ gente $(\mathrm{x} 2=10,65)$ querer $(x 2=10,64)$ melhor $(x 2=9,9)$ Deus $(x 2=4,77)$ 
doença (x2 =3,56) também (x2=3,2) dar (x2=3,2), nesta classe a expressão do viver é muito forte, a vida é normal e precisa ser vivida resistindo às intempéries que se apresentam dia-a-dia. As palavras viver, querer, melhor e Deus expressam que as pessoas tem o forte desejo de querer viver melhor e este pode estar ancorado em elementos relacionados à espiritualidade/religiosidade representados por Deus, como também expressado na classe anterior.

A espiritualidade e/ou a religião foram relatadas nas falas destacando-se então como uma fonte de apoio. A infecção pelo HIV trouxe para alguns indivíduos uma aproximação com a fé, servindo como ponto de apoio para a superação do diagnóstico fazendo brotar forças para aceitarem sua condição e cuidarem de $\mathrm{si}^{3}$. Isso gera comportamentos e sentimentos de fé, esperança e paz trazendo diferentes significados para a vida de cada um. Na área da saúde maiores níveis de satisfação com a vida, melhor estado de saúde e melhor qualidade de vida e bem-estar estão ligados à espiritualidade mesmo quando associados aos sintomas do HIV/Aids9. Mais de cinquenta anos com a doença e está vivendo, porque eu não posso viver também, eu tenho que esperar em Deus. (*suj_27). A fé numa força superior não retira do indivíduo sua parcela de responsabilidade e coparticipação, estes devem estar participando ativamente na promoção de sua saúde e bem-estar entendendo a necessidade de se manter o tratamento e acompanhamento devido à cronicidade da doença. Essa vontade de se manter vivo, também se expressa com elementos de fé e religiosidade, Deus aparece nas falas como um elemento que induz forças e alimenta esperança Se agarre com Deus, acho que não tem coisa melhor de que a gente se agarrar com Deus, $e$ tem que querer viver também, porque não adianta você se agarrar com Deus e deixar tudo para lá. (*suj_42).

$\mathrm{O}$ otimismo e a disposição contribuem para o aumento da capacidade de enfrentamento da doença e podem favorecer o retardamento da progressão da mesma A gente tem que querer viver, e acreditar na vida, coisa melhor do que viver não tem, eu sou muito assim, eu sou uma pessoa muito para cima para eu chegar a cair, à coisa tem que está ruim muito ruim. (*suj_42) o cuidado pessoal,o aumento da auto estima e do amor próprio pode ser observado após o diagnóstico, onde aparece uma valorização da existência ${ }^{3}$.

A aids não é vista aqui como uma doença terminal, é comparada a outras doenças crônicas onde o indivíduo precisa modificar alguns hábitos, seguir algumas regras e continuar vivendo. Quando esta é associada a doenças como, por exemplo, o diabetes estendem a ela uma configuração de doença crônica, tratável por meio de subsídios do governo e que de certa forma traz a sobrevida e supera a morte ${ }^{(3)}$ Ele só tem que adaptar a vida dele, é como se ele tivesse tido uma diabete, doença nenhuma a gente quer ter, mas se ela apareceu você deve adaptar a sua vida a ela, você não pode é desistir de viver, eu acho. (*suj 43)

A motivação para viver é o que impulsiona o seguimento do caminho do tratamento e esta deve estar presente nas abordagens feitas principalmente pelos profissionais de saúde que acompanham o paciente. Suas motivações, dificuldades, dúvidas e anseios frente à vida devem sempre ser objetos de conversa e partilhamento a fim de favorecer acolhimento e escuta para favorecer o convívio com a enfermidade .

\section{Conclusão}

A síndrome trilhou um longo caminho de meados de 80 até os dias atuais emergiu como letal e aguda e caminhou para doença crônica e tratável, todavia não perdeu o estigma e mantém uma bagagem de preconceito explícito e/ou velado por todos os segmentos sociais, desta forma, viver com HIV com certeza não é fácil, e muitos são os desafios enfrentados por quem convive com o vírus.

A depressão e perda da vontade de viver podem acontecer no momento imediato da descoberta da soropositividade, a medida que o tempo passa a PVHIV começa um processo de reconstrução e ressignificação da vida, e observou- se neste estudo que isto ocorre com a ancoragem no trabalho e na religiosidade/ espiritualidade , a rede social de apoio (amigos e familiares) tambem colaboram no refazimento das atividades diárias. Apoio e acolhimento favorecem essa retomada da vida, e neste contexto os profissionais de saúde representam um pilar de apoio principalmente no momento da descoberta da soropositividade. O profissional enfermeiro deve estar atento mobilizado e sensibilizado para entender que as representações sociais da doença ao longo desses anos estão em constante mudança levando a necessidade de ter uma prática reflexiva baseada em evidências e em humanidade.

Concluimos com este estudo que PVHIV passam por um momento inicial de ideias negativas, camimhando paulatinamente para um equilíbrio de viver a vida com uma doença crônica, com tratamento e acompanhamento constantes se fortalecendo com esperança.

\section{Referências}

1. UNAIDS. Joint United Nations Programme on HIV/AIDS . Knowledge is power - Know your status, know your viral load. 2018.

2. Brasil. Ministério da Saúde. Boletim epidemiológico: HIV AIDS 2018 Julho/2017 a junho/ 2018. Vol,49. No 53. 2018.

3. Braga RM de O, Lima TP, Gomes AMT, Oliveira DC de, Spindola T, Marques SC. Representações sociais do HIV/AIDS para as pessoas que convivem com a síndrome [Social representations of HIV/AIDS for people living with the syndrome]. Revista Enfermagem UERJ [Internet]. 30 de abril de 2016. Disponível em: http://www.e-publicacoes.uerj.br/index.php/ enfermagemuerj/article/view/15123 
4. Nascimento ARA, Menandro PRM. Análise lexical e análise de conteúdo: uma proposta de utilização conjugada. Estudos e pesquisas em psicologia, v. 6, n. 2, p. $72-88,2006$.

5. Camargo BV, Justo AM. IRAMUTEQ: Um software gratuito para análise de dados textuais. Temas em Psicologia. 2013;21(2):513-8.

6. De Andrade Moraes DC, De Oliveira RC, Arruda do Prado AV, Cabral JDR, Corrêa CA, Barbosa de Albuquerque MM. O conhecimento de pessoas vivendo com HIV/AIDS sobre a Terapia Antirretroviral. Enfermería Global. 30 de dezembro de 2017;17(1):96.

7. Vasconcelos MF de, Costa SFG da, Batista PS de S, Lopes MEL. Cuidados paliativos para o paciente com HIV/Aids: observâncias éticas adotadas por enfermeiros.Revista Enfermagem UERJ [Internet]. 30 de abril de 2016 Disponível em: http://www.e-publicacoes.uerj.br/index.php/ enfermagemuerj/article/view/26409

8. do Espirito Santo, C. C. et al. Adesão ao tratamento antirretroviral e a espiritualidade de pessoas com HIV/AIDS: estudo de representacoes sociais. Enfermagem Uerj, Rio de Janeiro, v. 21, n. 4, p. 458-464, 2013.

9. Costa TL da, Oliveira DC de, Formozo GA. Qualidade de vida e AIDS sob a ótica de pessoas vivendo com o agravo: contribuição preliminar da abordagem estrutural das representações sociais. Cadernos de Saúde Pública. fevereiro de 2015;365-76.

10. Oliveira AD de F, Vieira MCA, Silva SPC e, Mistura C, Jacobi CDS, Lira MO de SC e. Effects of HIV in daily life of women living with AIDS. Revista de Pesquisa: Cuidado é Fundamental Online. $1^{\circ}$ de janeiro de 2015;7(1):1975 